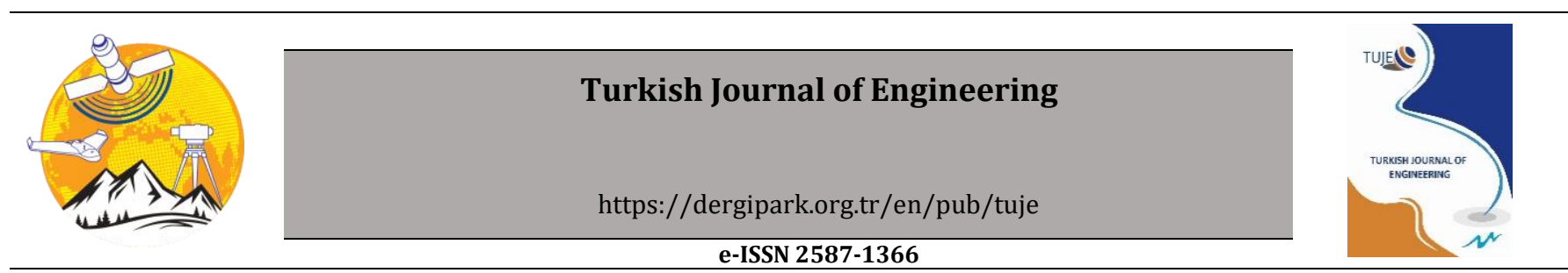

\title{
Fuzzy-Optimized model reference adaptive control of interacting and noninteracting processes based on MIT and Lyapunov rules
}

\author{
Demilade D. Dinakin ${ }^{*}\left(\right.$, Peter 0. Oluseyi ${ }^{1}$ \\ ${ }^{1}$ University of Lagos, Faculty of Engineering, Department of Electrical and Electronics Engineering, Lagos, Nigeria
}

\author{
Keywords \\ Adaptation gain \\ Fuzzy Logic Control (FLC) \\ Lyapunov rule \\ MIT rule \\ Model reference \\ Adaptive control
}

\begin{abstract}
Various system parameter variations occur during operations in several existing process industries. These parameter variations result in process shifts, thus, requiring adequate control strategies to compensate for these alterations, which consequently maintain desired system response. A paradigm is the coupled tank systems; in such systems, the level and flow of liquid must be adequately controlled to maintain the reaction equilibrium as well as to avoid spillage or equipment damage. The model reference adaptive control (MRAC) is an adaptive control strategy that creates a control law, subject to an adaptation gain, which causes the system's plant to continuously track a reference model until a zero tracking error is achieved. The Massachusetts Institute of Technology (MIT) and Lyapunov approaches were used to develop the adaptation mechanism, which is used to adjust the parameters in the control law. Conventionally, a fixed value is adopted as the adaptation gain; however, the adaption gain can also be determined heuristically. The fuzzy logic control was used to optimally determine the value of the adaptation gain, which thus results in the fuzzy-optimized MRAC (FOMRAC) system. Consequently, these schemes were comparatively analysed for the control of the flow and level of liquid in coupled two-tank systems, arranged in noninteracting and interacting fashions. Using MATLAB/Simulink, results depicted that the FOMRAC systems had faster settling times in comparison with the fixed adaptation gain MRAC systems. Overall, the FOMRAC system based on Lyapunov rule yielded the lowest performance indices values. In addition, the scheme completely eliminated the overshoot that resulted from the implementation of the other schemes for the control of the interacting process.
\end{abstract}

\section{INTRODUCTION}

Process control (Coughanowr and LeBlanc 2009) is a branch of control engineering and chemical engineering that involves the implementation of industrial control systems or strategies to achieve its main objective which is to regulate the value of some quantity or parameter. Process control is utilized in various industries ranging from oil refining, petrochemicals, food processing, bottling, pulp and paper manufacturing, chemical manufacturing or processing, power generating, biotechnology, pharmaceuticals and so on.

One basic problem in the process industries is the control of the level and flow of liquid in multiple-tank systems (Atchaya 2017; Bhuvaneswari et al. 2012; Mamur et al. 2017; Nandhinipriyanka et al. 2018; Narayan and Srivastava 2013; Senthilkumar and Lincon 2012). Usually, liquid is pumped and stored into a tank and then pumped into a different tank(s) (Medewar et al. 2017). Such tanks are connected in series and can be arranged in an interacting or noninteracting manner. Taking a two-tank system as a case study, the liquid level of tank 2 has no effect on the liquid level of tank 1 in a noninteracting arrangement. On the other hand, the liquid levels of both tanks affect each other in an interacting setup. It is highly imperative that the level and flow of liquid in such tanks are regulated so as to maintain the reaction equilibrium and to avoid spillage or equipment damage (Damrudhar and Tanti 2016; Manohar et al. 2013).

There are different industrial control strategies which include: open-loop control, feed-forward control, closedloop control, etc. In open-loop control, the system's output has no effect on the control action and is entirely dependent on the input signal. The feed-forward control 
uses a process model to predict and reduce the impact/influence of measured disturbances on the plant/process. The feedback control involves introducing a feedback loop to a system, thus, creating a control action that enables the system to achieve a desired output response. The block diagram representation is shown in Fig. 1.

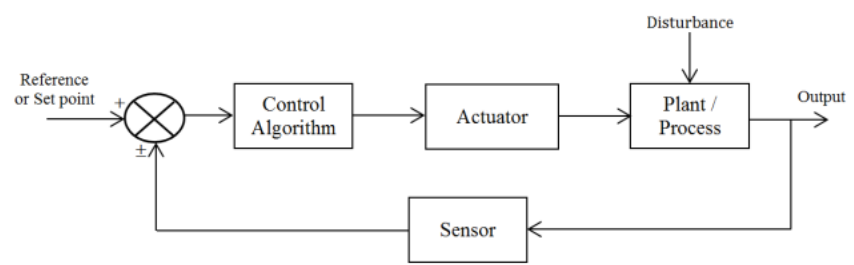

Figure 1. A typical industrial feedback control system

The proportional-integral-derivative (PID) controller is one of the widely used controllers in feedback control. Existing literature reveals numerous control techniques applied to coupled tank systems. In Changela and Kumar (2015); Fellani and Gabaj (2015); Parvat et al. (2015); Saju et al. (2014), the PID controller was used for liquid level control of various tank system setups using MATLAB software. Impressive results were recorded; however, it has been identified that adaptive control schemes are replacing the conventional control schemes because of the inadequacies experienced in coping with unanticipated disturbances or unpredictable faults (Stellet 2011). In other words, acting alone, the PID controller has a fixed gain thereby making it restricted in terms of adapting to external changes. Therefore, intelligent techniques, including meta-heuristic algorithms, have been used to tune the PID controller. Such include: particle swarm optimization (PSO-PID) (Medewar et al. 2017) internal model control (IMC-PID) (Lavanya et al. 2013; Senapati et al. 2018; Saju, et al. 2014; Jang 2017), approximate m-constant integral gain optimization (AMIGO-PID) (Senapati et al. 2018), Wiener model using Chidambaram technique (Saju, et al. 2014); Other control techniques used by other researchers include: the fuzzy logic control (FLC) (Changela and Kumar 2015; Parvat et al. 2015), PID-fuzzy (Senapati et al. 2018), model predictive control (Tijani et al. 2017), sliding mode control (SMC) (Ayten et al. 2018; Salunkhe, et al. 2015), back-stepping control strategy (John, et al. 2015), etc.

A feedback control system that adjusts its characteristics in a control environment so that some specified criteria are satisfied is known as an adaptive control system. Adaptive control systems are either model reference or self-tuning (Zhang 2010). The model reference adaptive control (MRAC) or model reference adaptive system (MRAS) tunes the controller parameters using a model of the plant (reference model). There are several approaches to tuning these parameters which include: the Massachusetts Institute of Technology (MIT) rule (Jain and Nigam 2013), Lyapunov rule (Nasar et al. 2015), etc.

The MIT rule is a gradient approach to the analysis and design of MRAC systems. It involves defining an error signal, which is the difference between the plant's output and the reference model's output. This error signal is used to tune the controller parameters by defining an objective function. The parameters of the controller are adjusted in the direction of the negative gradient of the objective function. It should be noted that the adaptive control loop of the MRAC system designed using the MIT rule has the tendency to be unstable. The Lyapunov approach, however, guarantees a stable adaptive control law. The Lyapunov approach is achieved using a Lyapunov function of both the output error or state error and the parameter error. The stability of the control loop is guaranteed if the derivative of the Lyapunov function is negative definite (Astrom and Wittenmark 1989; Dumont 2011).

The MIT and Lyapunov approaches are used to develop the adaptation mechanism which is used to adjust the parameters in the control law (Pankaj et al. 2011). This parameter adjustment results in a zero error and ensures system stability. The system performance is influenced by the adaptation gain from the adaptation mechanism (Stellet 2011; Swarnkar et al. 2011). A large value of adaptation gain can cause system instability. As seen in Stellet (2011), the MRAC system was used to control the liquid level in a coupled tank system and results were taken for different selected adaptation gains and compared with the result of implementing the PID controller. It was observed that for lower adaptation gains, the PID controller performed better than the MRAC whereas the MRAC performed better for slightly higher adaptation gain. This, thus, indicates that the adaptation gain must be optimally chosen to eliminate this poor performance. Usually, the adaptation gain is determined heuristically (Cheung 1996; Cheung et al. 1996; Keerth and Sathyanarayana 2012; Zadeh 1975). A heuristic approach adequate enough for determining the adaptation gain is the FLC. The FLC is a knowledge based algorithm which involves using linguistic variables to obtain optimal solution to a control problem (Zadeh 1975).

This study seeks to use the FLC to heuristically determine the adaptation gain of the MRAC systems for optimal performance. First, the coupled two-tank systems in noninteracting and interacting setups are modeled. The transfer function representations of both models are afterwards derived and then the MIT and Lyapunov approaches are used to design the MRAC systems for the control of both coupled two-tank systems. The performance of fuzzy-optimized model reference adaptive control (FOMRAC) systems based on both approaches is comparatively analyzed with the performance of the fixed adaptation gain MRAC systems using the following performance indices: integral square error (ISE), integral absolute error (IAE), integral time squared error (ITSE) and integral time absolute error (ITAE). The simulation is performed using MATLAB/Simulink.

The organization of the paper is as follows: Section 2 presents the mathematical models of the coupled tank systems and gives detailed description of the development of the control systems. Section 3 presents the investigations of the software implementation of the control techniques on the coupled tank systems using different performance indices. The paper is finally concluded in Section 4. 


\section{RESEARCH METHOD}

Figure 2 shows the models of noninteracting and interacting coupled two-tank systems. The topology is a series arrangement. Liquid flows, first, into Tank 1 then into Tank 2. The outlet of each tank has a concentrated flow resistance dominated by a valve. The aim is to control the level of liquid in Tank 2. From Fig. $2, h_{1}$ and $h_{2}$ are the heights (in $\mathrm{m}$ ) of Tank 1 and Tank 2 respectively; $q_{0}$ is the volumetric flow of liquid (in $\mathrm{m}^{3} / \mathrm{s}$ ) into Tank 1 while $q_{1}$ and $q_{2}$ are the volumetric flow of liquid (in $\mathrm{m}^{3} / \mathrm{s}$ ) out of Tank 1 and Tank 2 respectively. The outlet of each tank has a concentrated flow resistance dominated by a valve. $R_{1}$ and $R_{2}$ are the resistances to flow of liquid (in $\mathrm{s} / \mathrm{m}^{2}$ ) out of Tank 1 and Tank 2 respectively. The crosssectional areas $\left(\mathrm{in}^{2}\right.$ ) of Tank 1 and Tank 2 respectively are denoted by $\mathrm{A}_{1}$ and $\mathrm{A}_{2}$.

Applying mass balance equation, the transfer function of the noninteracting coupled tank system [Fig. $2(a)]$ is given by Eq. (1):

$$
\frac{h_{2}(s)}{q_{0}(s)}=\frac{R_{2}}{\left(\tau_{1} s+1\right)\left(\tau_{2} s+1\right)}
$$

Similarly, applying mass balance equation and assuming linear resistance to flow, the transfer function of the interacting coupled tank system [Fig. 2(b)] is given by Eq. (2):

$$
\frac{h_{2}(s)}{q_{0}(s)}=\frac{R_{2}}{\tau_{1} \tau_{2} s^{2}+\left(\tau_{1}+\tau_{2}+A_{1} R_{2}\right) s+1}
$$

The parameters used to model both coupled two-tank systems, extracted from Damrudhar and Tanti (2016); Fellani and Gabaj (2015) are shown in Table 1.

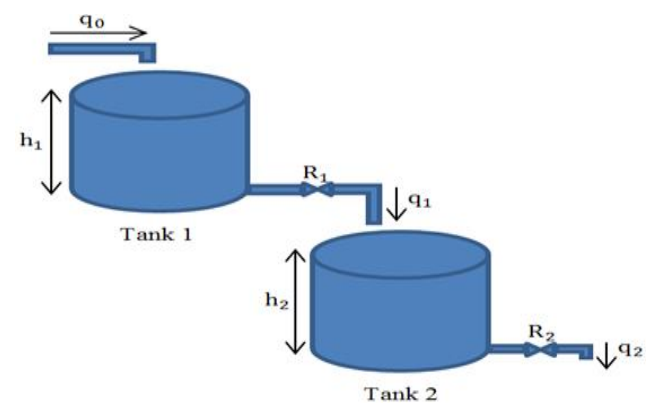

(a) noninteracting

Figure 2. Coupled two-tank systems

\subsection{Model Reference Adaptive Control (MRAC) System}

The block diagram of a typical MRAC system is shown in Fig. 3. It consists of two loops; a feedback loop and a parameter adjustment loop. Where, $u_{c}$ is the reference or set point, $y_{m}$, is the output of the reference model, $\mathrm{y}$ is the output of the plant while $\mathrm{u}$ is the input to the
Table 1. Parameters used to model both coupled twotank systems

\begin{tabular}{ccc}
\hline Parameter & Value & Unit \\
\hline$A_{1}$ & 0.025 & $\mathrm{~m}^{2}$ \\
$A_{2}$ & 0.025 & $\mathrm{~m}^{2}$ \\
$R_{1}$ & 100 & $\mathrm{~s} / \mathrm{m}^{2}$ \\
$R_{2}$ & 200 & $\mathrm{~s} / \mathrm{m}^{2}$ \\
$h_{1}$ & 0.3 & $\mathrm{~m}$ \\
$h_{2}$ & 0.15 & $\mathrm{~m}$ \\
$\tau_{1}$ & 2.5 & $\mathrm{~s}$ \\
$\tau_{2}$ & 5 & $\mathrm{~s}$ \\
\hline
\end{tabular}

Substituting the parameters in Table 1 in the expressions in Eq. (1) and Eq. (2), the transfer functions of the noninteracting and interacting coupled tank systems respectively are:

$$
\begin{gathered}
\frac{h_{2}(s)}{q_{0}(s)}=\frac{200}{(2.5 s+1)(5 s+1)}=\frac{200}{12.5 s^{2}+7.5 s+1} \\
\frac{h_{2}(s)}{q_{0}(s)}=\frac{200}{12.5 s^{2}+(2.5+5+5) s+1}=\frac{200}{12.5 s^{2}+12.5 s+1}
\end{gathered}
$$

The poles of Eq. (3) are located at -0.2 and -0.4 while the poles of Eq. (4) are located at -0.0877 and -0.9123 . Comparing Eq. (3) and Eq. (4) with the standard form of second order systems in Eq. (5),

$$
\frac{C(s)}{R(s)}=\frac{K \omega_{n}^{2}}{s^{2}+2 \zeta \omega_{n} s+\omega_{n}^{2}}
$$

Both systems have gains, $K$, of 200 and natural frequencies, $\omega_{n}$, of 0.2828 . The damping ratios of the noninteracting and interacting systems respectively are 1.0607 and 1.7678. A system with a damping ratio greater than one indicates an over-damped system. Overdamped systems approach a steady state more slowly than critically damped systems.

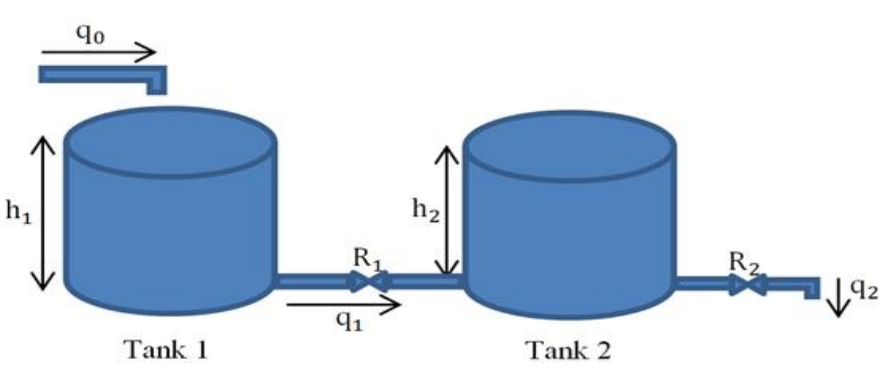

(b) interacting

plant/process and is the control law, which is a function of the adaptation parameters. A reference model is used to tune the parameters of the controller thus, adjusting the control law which makes the plant/process track the output, $y_{m}$, of the reference model. There are a number of approaches that can be used to determine the adjustment mechanism or adaptation law of the MRAC system. Two of such are the MIT and Lyapunov approaches. 


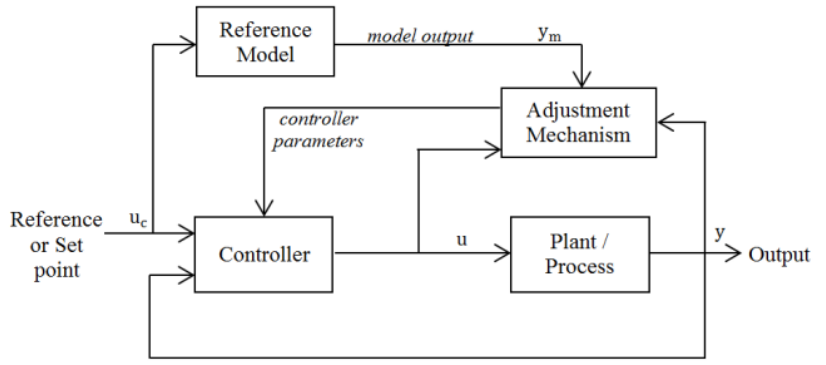

Figure 3. Block diagram of model reference adaptive control system

\subsubsection{Lyapunov and MIT rules}

Both coupled tank setups are second order systems as seen in Eq. (3) and Eq. (4). But first, the adaptation mechanism for a first order system using the Lyapunov rule is derived. The Lyapunov rule guarantees a stable adaptive control law. Considering a first order plant given by:

$$
\frac{d y}{d t}=-a y+b u
$$

A reference model is given by:

$$
\frac{d y_{m}}{d t}=-a_{m} y_{m}+b_{m} u_{c}
$$

The control law is given by:

$$
u=\theta_{1} u_{c}-\theta_{2} y
$$

The error function is the difference between the output of the plant, $y$, and the output of the reference model, $y_{m}$. This is expressed as:

$$
e=y-y_{m}
$$

By mathematical derivations, Eq. (10) is obtained,

$$
\dot{e}=-a_{m} e-\left(b \theta_{2}+a-a_{m}\right) y+\left(b \theta_{1}-b_{m}\right) u_{c}
$$

The Lyapunov approach requires a Lyapunov function; the function, $V$, must be positive definite while its derivative, $\dot{V}$, must be negative definite. It should be noted that there is no systematic way of finding a suitable Lyapunov function, $V$, (Astrom and Wittenmark 1989). Choosing the Lyapunov function:

$$
V\left(e, \theta_{1}, \theta_{2}\right)=\frac{1}{2}\left(e^{2}+\frac{1}{b \gamma}\left(b \theta_{2}+a-a_{m}\right)^{2}+\frac{1}{b \gamma}\left(b \theta_{1}-b_{m}\right)^{2}\right)
$$

Differentiating the Lyapunov function and substituting Eq. (10),

$$
\dot{\mathrm{V}}=-\mathrm{a}_{\mathrm{m}} \mathrm{e}^{2}+\frac{1}{\gamma}\left(\mathrm{b} \theta_{2}+\mathrm{a}-\mathrm{a}_{\mathrm{m}}\right)\left(\dot{\theta}_{2}-\gamma \mathrm{ye}\right)+\frac{1}{\gamma}\left(\mathrm{b} \theta_{1}-\mathrm{b}_{\mathrm{m}}\right)\left(\dot{\theta}_{1}+\gamma \mathrm{u}_{\mathrm{c}} \mathrm{e}\right)
$$

To ensure that $\dot{V}$ is negative definite,

$$
\frac{1}{\gamma}\left(b \theta_{2}+a-a_{m}\right)\left(\dot{\theta}_{2}-\gamma y e\right)+\frac{1}{\gamma}\left(b \theta_{1}-b_{m}\right)\left(\dot{\theta}_{1}+\gamma u_{c} e\right)=0
$$

Therefore, the adaptation laws using the Lyapunov approach are:

$$
\begin{gathered}
\frac{\partial \theta_{1}}{\partial \mathrm{t}}=-\gamma \mathrm{u}_{\mathrm{c}} \\
\frac{\partial \theta_{2}}{\partial \mathrm{t}}=\gamma \mathrm{ye}
\end{gathered}
$$

The MIT rule for a first order system is also derived. This is achieved using the error function in Eq. (10). Then, an objective function, $J$, is defined which is given by:

$$
\begin{gathered}
\mathrm{J}(\theta)=\frac{1}{2} \mathrm{e}^{2} \\
\frac{\partial \mathrm{J}}{\partial \mathrm{e}}=\mathrm{e}
\end{gathered}
$$

The adaptation parameters are then adjusted in the direction of the negative gradient of the objective function, $J$. Therefore,

$$
\frac{\mathrm{d} \theta}{\mathrm{dt}}=-\gamma \frac{\partial \mathrm{J}}{\partial \theta}=-\gamma \mathrm{e} \frac{\partial \mathrm{e}}{\partial \theta}
$$

Using the first order system, reference model and control law expressed by Eq. (6), Eq. (7) and Eq. (8) respectively. A perfect model means that $y=y_{m}$. Therefore,

$$
\begin{gathered}
\theta_{1}=\frac{\mathrm{b}_{\mathrm{m}}}{\mathrm{b}} \\
\theta_{2}=\frac{\mathrm{a}_{\mathrm{m}}-\mathrm{a}}{\mathrm{b}}
\end{gathered}
$$

From Eq. (18),

$$
\begin{aligned}
& \frac{\mathrm{d} \theta_{1}}{\mathrm{dt}}=-\gamma \mathrm{e} \frac{\partial \mathrm{e}}{\partial \theta_{1}} \\
& \frac{\mathrm{d} \theta_{2}}{\mathrm{dt}}=-\gamma \mathrm{e} \frac{\partial \mathrm{e}}{\partial \theta_{2}}
\end{aligned}
$$

Substituting Eq. (8) in Eq. (6) and taking the Laplace transform,

$$
y(s)=\frac{b \theta_{1}}{s+a+b \theta_{2}} u_{c}
$$

Taking the Laplace transform of Eq. (7),

$$
\mathrm{y}_{\mathrm{m}}(\mathrm{s})=\frac{\mathrm{b}_{\mathrm{m}}}{\mathrm{s}+\mathrm{a}_{\mathrm{m}}} \mathrm{u}_{\mathrm{c}}
$$

Substituting Eq. (23) and Eq. (24) in Eq. (9),

$$
\begin{gathered}
e(s)=\frac{b \theta_{1}}{s+a+b \theta_{2}} u_{c}-\frac{b_{m}}{s+a_{m}} u_{c} \\
\frac{\partial e}{\partial \theta_{1}}=\frac{b}{s+a+b \theta_{2}} u_{c}
\end{gathered}
$$

Substituting Eq. (20),

$$
\frac{\partial \mathrm{e}}{\partial \theta_{1}}=\frac{\mathrm{b}}{\mathrm{s}+\mathrm{a}_{\mathrm{m}}} \mathrm{u}_{\mathrm{c}}
$$




$$
\frac{\partial \mathrm{e}}{\partial \theta_{2}}=-\frac{\mathrm{b}^{2} \theta_{1}}{\left(\mathrm{~s}+\mathrm{a}+\mathrm{b} \theta_{2}\right)^{2}} \mathrm{u}_{\mathrm{c}}
$$

Substituting Eq. (23) and Eq. (20),

$$
\frac{\partial e}{\partial \theta_{2}}=-\frac{b}{s+a_{m}} y
$$

Substituting Eq. (27) and Eq. (29) in Eq. (21) and Eq. (22) respectively, the adaptation laws using the MIT rule are:

$$
\begin{gathered}
\frac{d \theta_{1}}{d t}=-\gamma^{\prime} e \frac{b}{s+a_{m}} u_{c} \\
\frac{d \theta_{2}}{d t}=\gamma^{\prime} e \frac{b}{s+a_{m}} y
\end{gathered}
$$

Since the parameter, $b$, is unknown, it is absorbed using the equation: $\gamma=\gamma^{\prime} b / a_{m}$. Equation (30) and Eq. (31) become Eq. (32) and Eq. (33) respectively.

$$
\begin{gathered}
\frac{d \theta_{1}}{d t}=-\gamma e \frac{a_{m}}{s+a_{m}} u_{c} \\
\frac{d \theta_{2}}{d t}=\gamma e \frac{a_{m}}{s+a_{m}} y
\end{gathered}
$$

Comparing the adaptation laws obtained using the Lyapunov and MIT rules, it is observed that they are both identical except that the MIT rule introduces a filter which is equivalent to the transfer function of the reference model (Pankaj et al. 2011). Now, considering a second order system,

$$
\ddot{y}=-a \dot{y}-b y+b u
$$

With a reference model,

$$
\ddot{y}_{\mathrm{m}}=-\mathrm{a}_{\mathrm{m}} \dot{\mathrm{y}}_{\mathrm{m}}-\mathrm{b}_{\mathrm{m}} \mathrm{y}_{\mathrm{m}}+\mathrm{b}_{\mathrm{m}} \mathrm{u}_{\mathrm{c}}
$$

By following the procedure utilized above, the adaptation law for a second order system using the MIT rule is given by:

$$
\begin{gathered}
\frac{d \theta_{1}}{d t}=-\gamma e \frac{b_{m}}{s^{2}+a_{m} s+b_{m}} u_{c} \\
\frac{d \theta_{2}}{d t}=\gamma e \frac{b_{m}}{s^{2}+a_{m} s+b_{m}} y
\end{gathered}
$$

Again, the adaptation laws for a second order system using MIT rule introduces a filter, which is the transfer function of the second order reference model. It can therefore be concluded that the adaptation laws, using the Lyapunov approach, for the first order system holds for the second order system. The adaptation gain, $\gamma$, determines the performance of the plant and is usually determined heuristically. This gain is determined using the FLC.

\subsection{Fuzzy Logic Control (FLC)}

Fuzzy logic control is a knowledge-based control strategy and it basically involves three stages which include: fuzzification, inference process and defuzzification (Amat et al. 2018; Dinakin and Oluseyi 2018; Mekhanet et al. 2016). The mapping of the input and output variables into membership functions is called fuzzification. The inference process involves formulating a mapping, by the utilization of a rule-base, from which decisions can be made (MATLAB 2016). It should be noted that there is no systematic tool for the formulation of the rule-base of the FLC (Reusch 1997). The final stage of the FLC is defuzzification and it involves converting the fuzzy output into a crisp or quantifiable value.

The error, $e$, which is the difference between the output of the plant and the output of the reference model, and the rate of change of error, $e^{\prime}$, are taken as the fuzzy inputs while the adaptation gain, $\gamma$ from the adaptation law is the fuzzy output. This is shown in Fig. 4.

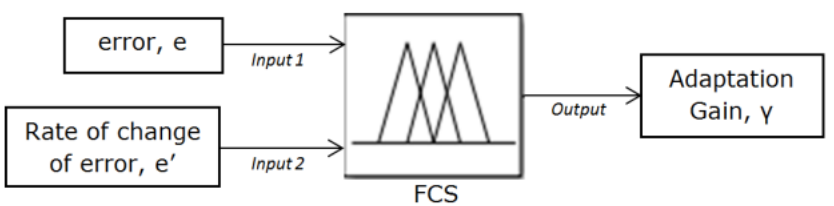

Figure 4. Input and output variables for fuzzy control system

The inputs, $e$ and $e^{\prime}$, are mapped, using equally spaced Gaussian membership functions (shown in Fig. 5), into the set negative high (NH), negative medium (NM), negative low (NL), zero (ZE), positive low (PL), positive medium (PM), positive high (PH) $\}$ while the output, $\gamma$ is mapped into the set zero (Z), low (L), medium (M), high (H)\}.

The rule-base is made up of IF-THEN rules which relate the inputs with the output. The rules used to determine the adaptation gain of the adaptation law/mechanism are shown in Table 2. For instance, if error is $\mathrm{NH}$ and rate of change of error is $\mathrm{NH}$, then the adaptation gain is $\mathrm{H}$. If error is PL and rate of change of error is $\mathrm{PM}$, then the adaptation gain is $\mathrm{M}$. If error is $\mathrm{ZE}$ and rate of change of error is $\mathrm{ZE}$, then the adaptation gain is $\mathrm{Z}$, and so on.

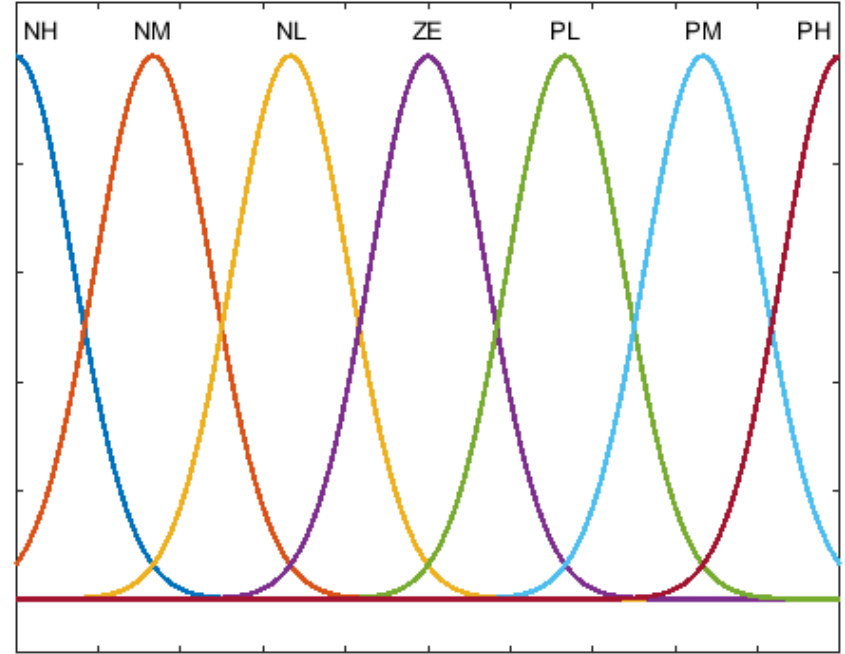

Figure 5. Gaussian membership function

The rules in Table 2 create a 3D surface plot as shown in Fig. 6.

The plant parameters of the MRAC system are obtained from Eq. (3) and Eq. (4) and shown in Table 3. 
Table 2. Rules relating the inputs with the output

\begin{tabular}{llllllll}
$\mathbf{e}^{\prime}$ & NH & NM & NL & ZE & PL & PM & PH \\
\hline NH & H & H & M & M & L & Z & Z \\
NM & H & M & M & L & L & Z & Z \\
NL & M & M & L & L & Z & Z & L \\
ZE & M & L & L & Z & L & L & M \\
PL & L & Z & Z & L & L & M & M \\
PM & Z & Z & L & L & M & M & H \\
PH & Z & Z & L & M & M & H & H \\
\hline
\end{tabular}

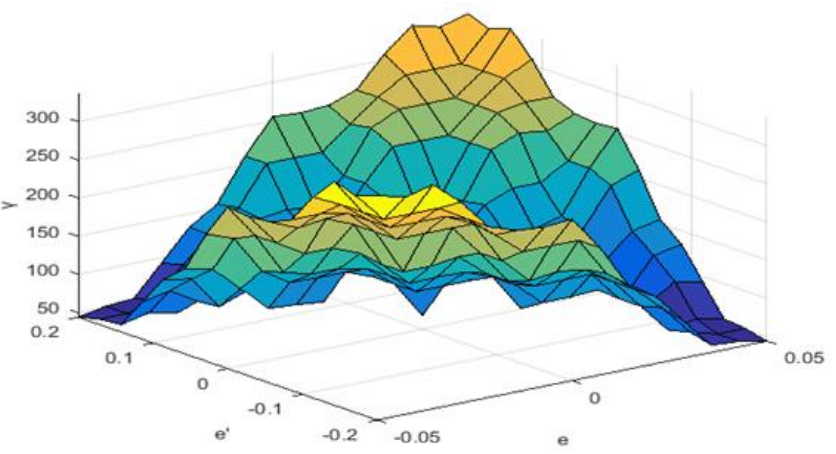

Figure 6. 3D rules' surface plot

Table 3. Plant parameters of the MRAC system

\begin{tabular}{lcc}
\hline System & Parameter & Value \\
\hline \multirow{2}{*}{ Noninteracting } & $a$ & 0.6 \\
& $b$ & 0.08 \\
\hline \multirow{2}{*}{ Interacting } & $a$ & 1 \\
& $b$ & 0.08 \\
\hline
\end{tabular}

It has already been established that both systems are over-damped systems. Therefore, a critically damped model is chosen so that the plants continuously track the model. Critically damped systems have repeated poles and a damping ratio of one. The model parameters are chosen and shown in Table 4.

Table 4. Model parameters of the MRAC system

\begin{tabular}{lcc}
\hline System & Parameter & Value \\
\hline \multirow{2}{*}{ Noninteracting } & $a_{m}$ & 0.8 \\
& $b_{m}$ & 0.16 \\
\hline \multirow{2}{*}{ Interacting } & $a_{m}$ & 2 \\
& $b_{m}$ & 1 \\
\hline
\end{tabular}

From Table 4, the transfer functions of the reference models of the noninteracting and interacting systems respectively are:

$$
\begin{gathered}
\frac{y_{m}(s)}{u_{c}(s)}=\frac{1}{6.25 s^{2}+5 s+1} \\
\frac{y_{m}(s)}{u_{c}(s)}=\frac{1}{s^{2}+2 s+1}
\end{gathered}
$$

This indicates that the models have repeated poles at -0.4 for the noninteracting system and at -1 for the interacting system. Fig. 7 shows the block diagrams representations of the overall transfer function of the MRAC systems of both the noninteracting and interacting coupled two-tank systems. The adaptation mechanisms for the noninteracting tank system using the MIT and Lyapunov rules are shown in Fig. 8.

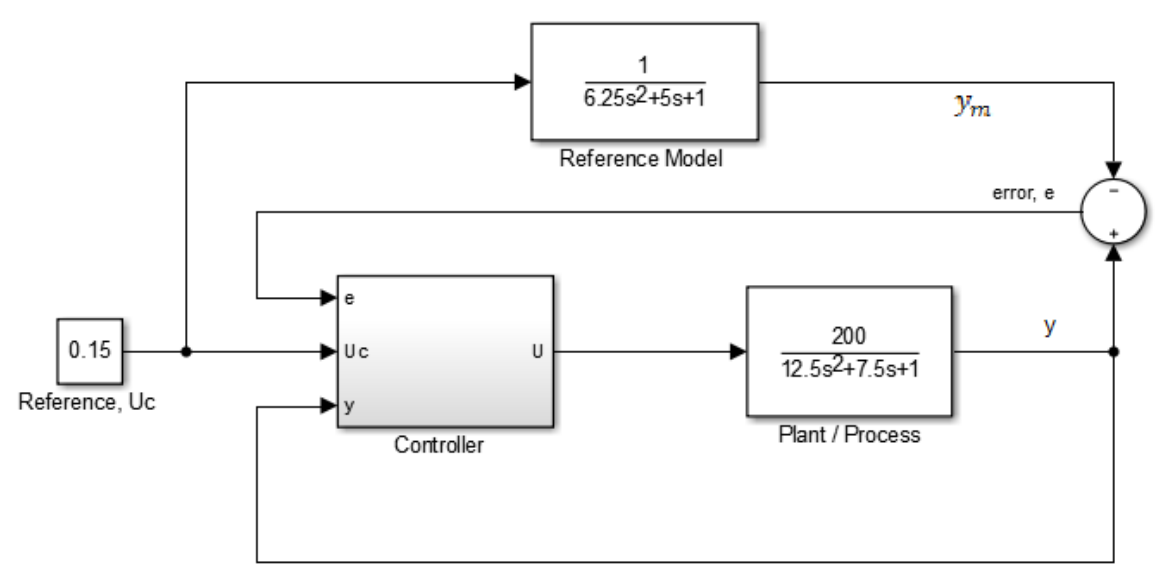

(a) noninteracting

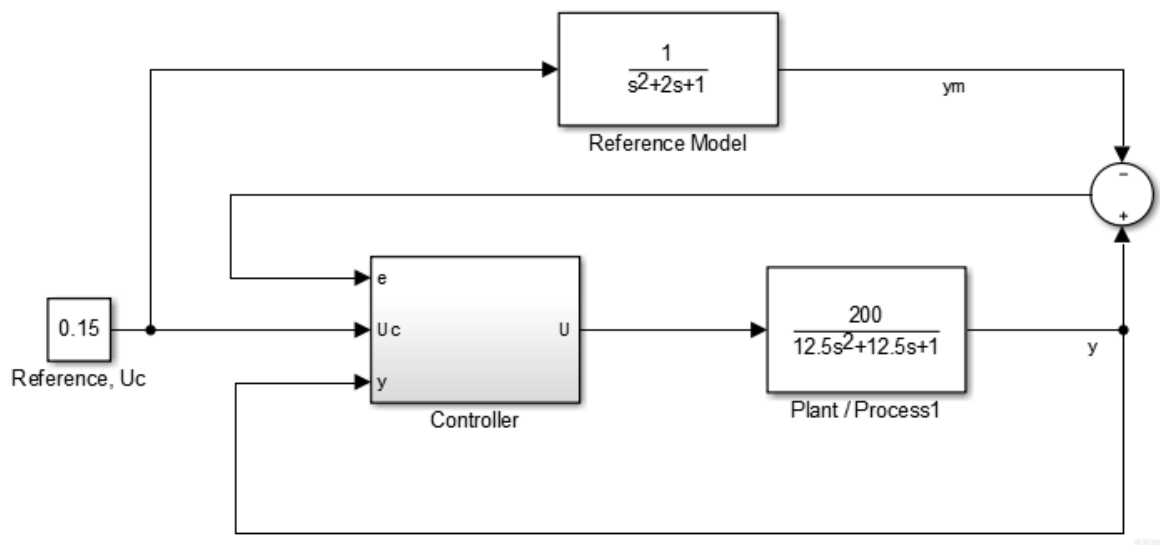

(b) interacting

Figure 7. Block diagram representation of the overall transfer function of the MRAC systems 


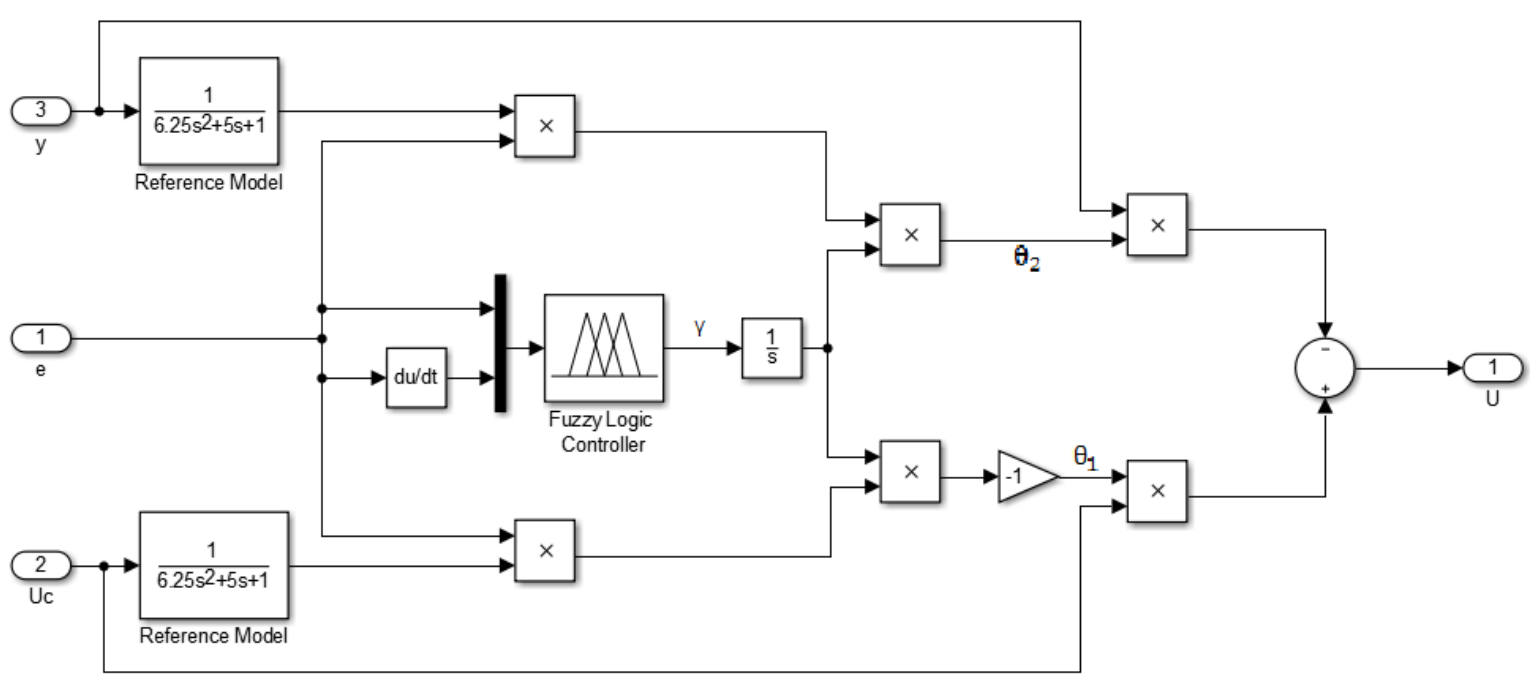

(a) MIT

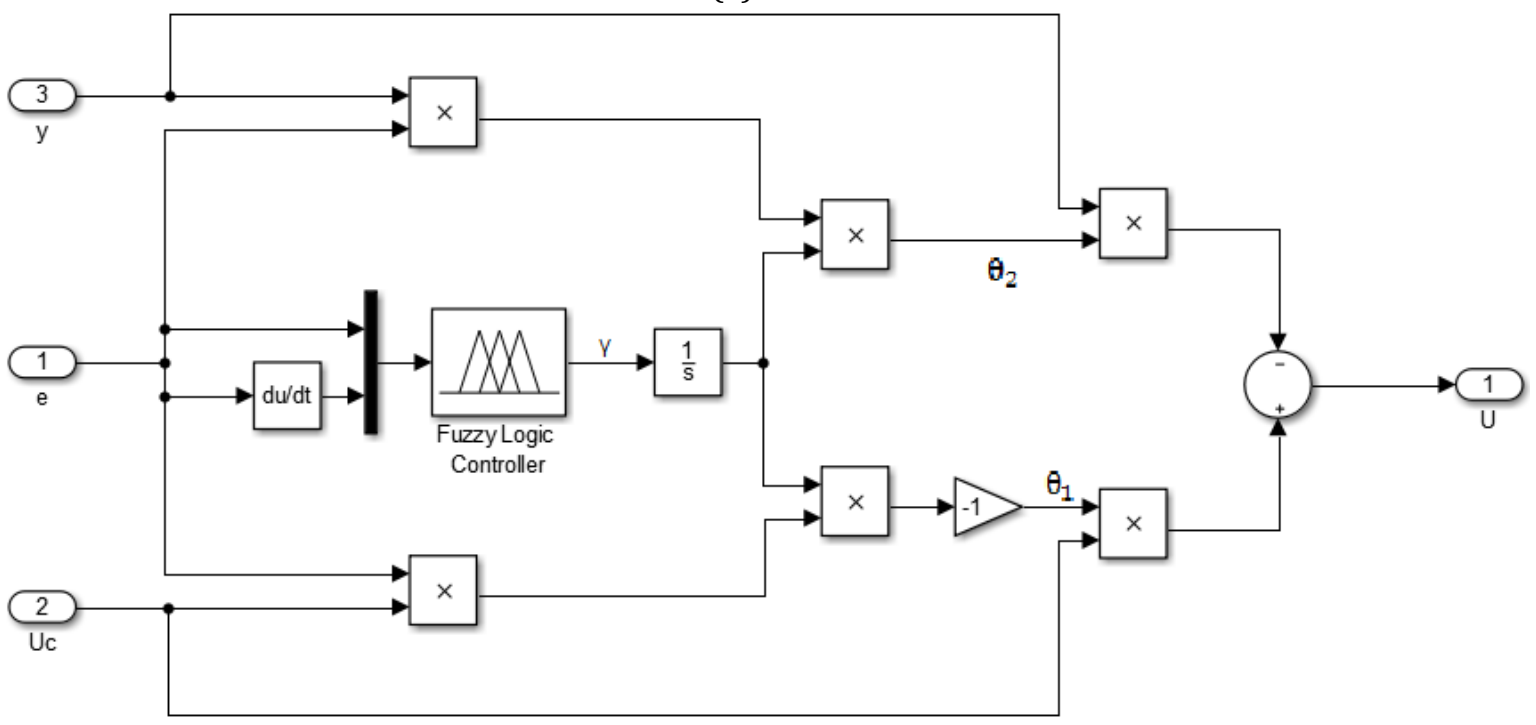

(b) Lyapunov

Figure 8. Adaptation mechanism fort he noninteracting tank systems

\subsection{Performance Analysis}

The performance of the FOMRAC systems designed using the MIT and Lyapunov approaches is compared with the performance of conventional fixed adaptation gain MRAC systems. The maximum adaptation gain value used in the design of the FLC is 400; hence, this value is used as the adaptation gain for the fixed adaption gain MRAC systems. The following performance indices are used for the comparative analysis of each controller: ISE, IAE, ITAE and ITSE. The formulas for the ISE, IAE, ITAE and ITSE respectively are given as follows:

$$
\begin{aligned}
\text { ISE } & =\int_{0}^{t} e(t)^{2} d t \\
\text { IAE } & =\int_{0}^{t}|e(t)| d t \\
\text { ITSE } & =\int_{0}^{t} t e(t)^{2} d t \\
\text { ITAE } & =\int_{0}^{t} t|e(t)| d t
\end{aligned}
$$

\section{RESULTS AND DISCUSSION}

Simulation is done using MATLAB/Simulink. The noninteracting and interacting coupled two-tank system is simulated with the designed controllers. The simulation is done for a period of 30 seconds. The set point which is the value of height, $h_{2}$, is $0.15 \mathrm{~m}$. Simulation is done first for the fixed adaptation gain MRAC controllers. The fuzzy logic controller is then used to optimize the adaptation gain. As the adaptation gain changes, the adaptation parameters $\left(\theta_{1}\right.$ and $\left.\theta_{2}\right)$ also change.

Figures 9 and 10 show the variations in the adaptation parameters for the MRAC systems with a fixed adaptation gain of 400 and for the FOMRAC systems respectively, based on the MIT rule.

For the fixed adaptation gain MRAC systems, it can be seen that the adaptation parameters converge to constant values of $+2.5002 \mathrm{E}-3$ and $-2.4939 \mathrm{E}-3$ for $\theta_{1}$ and $\theta_{2}$ respectively for the noninteracting tank system and constant values of $+2.5002 \mathrm{E}-3$ and $-2.4942 \mathrm{E}-3$ for $\theta_{1}$ and $\theta_{2}$ respectively for the interacting tank system. Likewise, for the FOMRAC systems, the adaptation parameters converge to constant values of $+2.4988 \mathrm{E}-3$ and $-2.4988 \mathrm{E}-3$ for $\theta_{1}$ and $\theta_{2}$ respectively for the 
noninteracting tank system and constant values of $2.5 \mathrm{E}-3$ and $-2.5 \mathrm{E}-3$ for $\theta_{1}$ and $\theta_{2}$ respectively for the interacting tank system.

Figures 11 and 12 show the variations in adaptation parameters for the noninteracting and interacting systems based on the Lyapunov rule for the fixed adaptation gain systems and FOMRAC systems respectively. The adaptation parameters also converge to constant values. For the fixed adaptation gain systems,

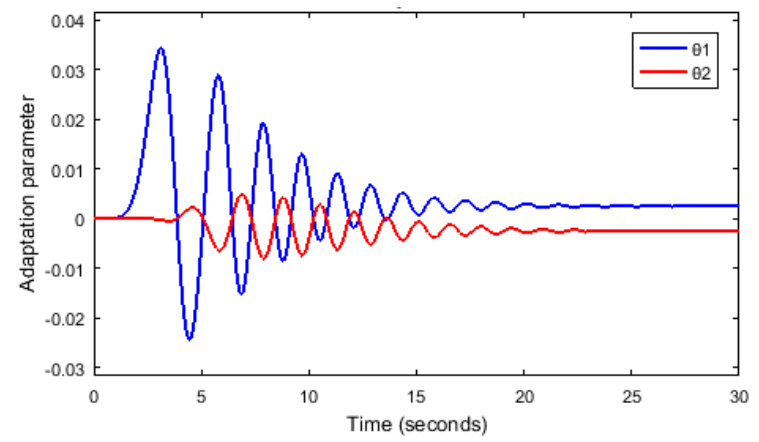

(a) noninteracting

Figure 9. Variations in adaptation parameters of the fixed adaptation gain MRAC systems based on MIT rule

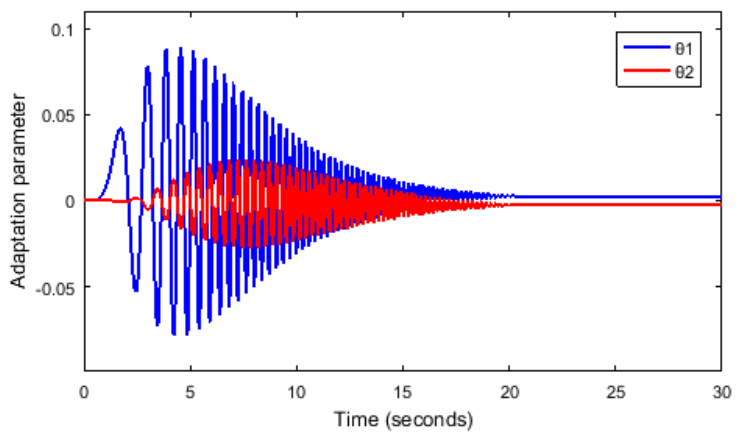

(a) noninteracting $\theta_{1}$ and $\theta_{2}$ converge to $2.4997 \mathrm{E}-3$ and $-2.4924 \mathrm{E}-3$ respectively for the noninteracting tank system and values of $2.5003 \mathrm{E}-2$ and $-2.4935 \mathrm{E}-2$ respectively for the interacting tank system. For the FOMRAC systems, $\theta_{1}$ and $\theta_{2}$ converge to $2.5416 \mathrm{E}-3$ and $-2.5416 \mathrm{E}-3$ respectively for the noninteracting tank system and values of $2.5588 \mathrm{E}-3$ and $-2.5588 \mathrm{E}-3$ respectively for the interacting tank system.

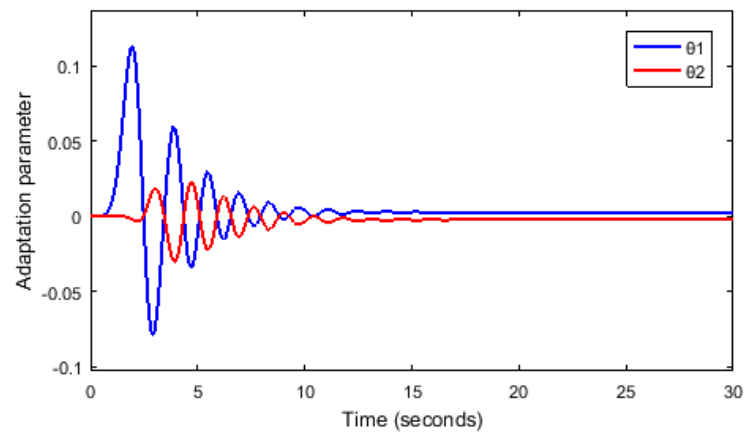

(b) interacting

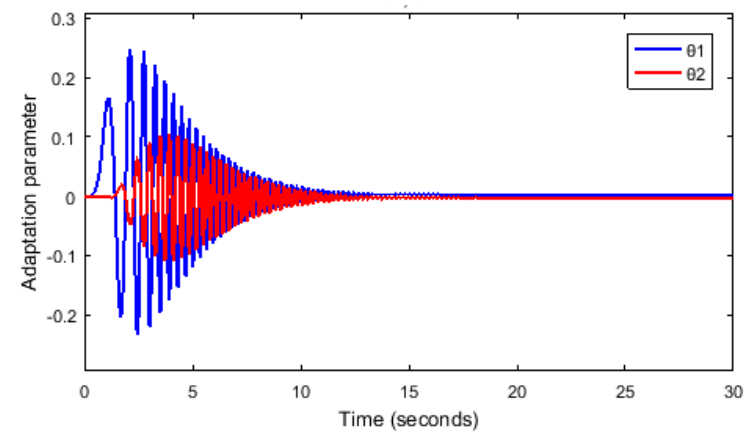

(b) interacting

Figure 10. Variations in adaptation parameters of the FOMRAC systems based on MIT rule

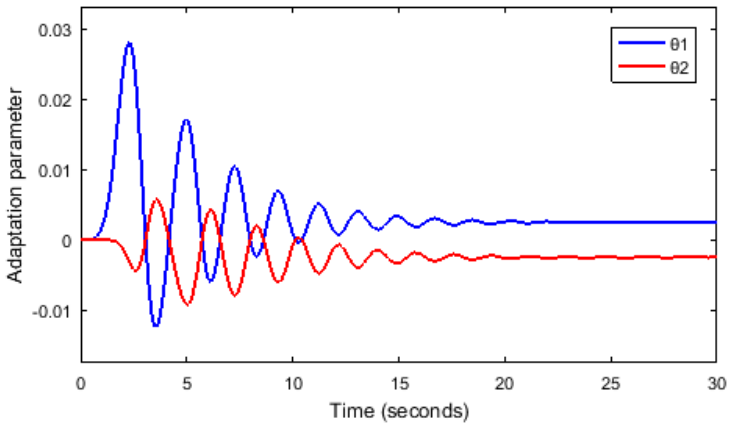

(a) noninteracting

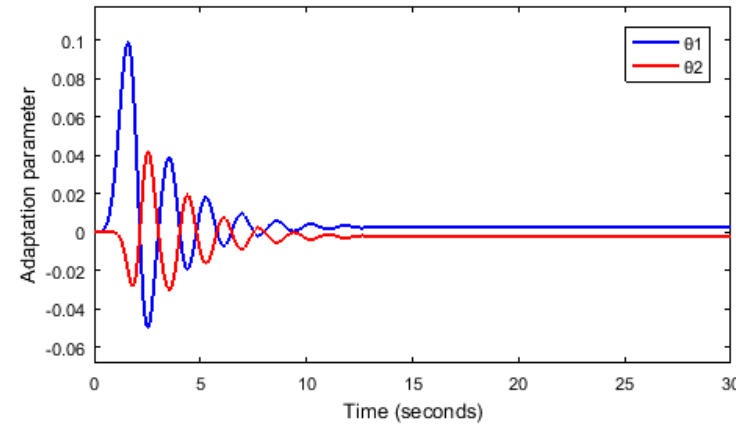

(b) interacting

Figure 11. Variations in adaptation parameters of the fixed adaptation gain MRAC systems based on Lyapunov rule

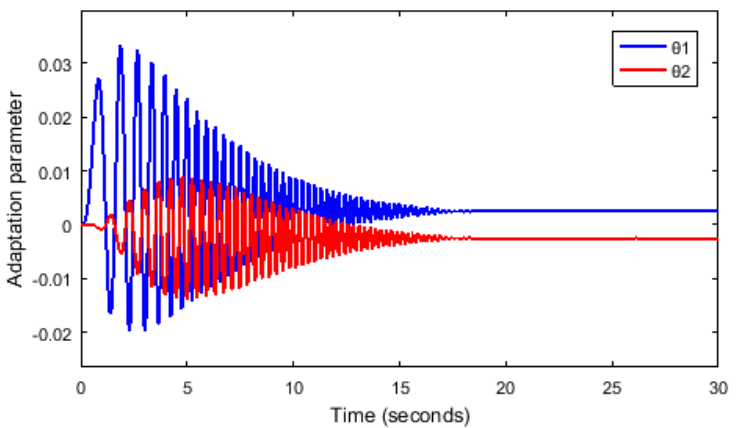

(a) noninteracting

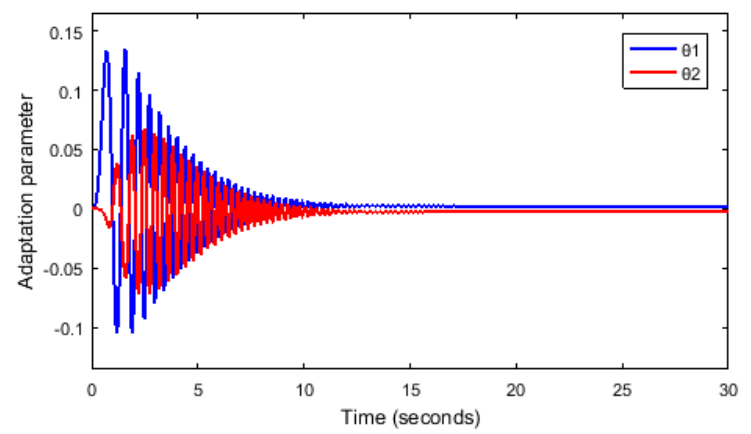

(b) interacting

Figure 12. Variations in adaptation parameters of the FOMRAC systems based on Lyapunov rule 
For MRAC, the control law is subject to a control parameter, $u$, which is a function of the adaptation parameters. The variation of the control parameters with time for the fixed adaptation gain MRAC systems and the FOMRAC systems respectively are shown in Figs. 13 and 14 respectively. It is also seen that, for the fixed adaptation gain MRAC system [Fig 13(a)], both control parameters converge to constant values; $7.4819 \mathrm{E}-4$ using the MIT rule and 7.4773E - 4 using Lyapunov rule. Likewise, for the FOMRAC system [Fig 14(a)]; 7.5E - 4 using the MIT rule and 7.3409E - 4 using the Lyapunov rule. The control parameters of the fixed adaptation gain system shown in Fig 13(b) and the FOMRAC system

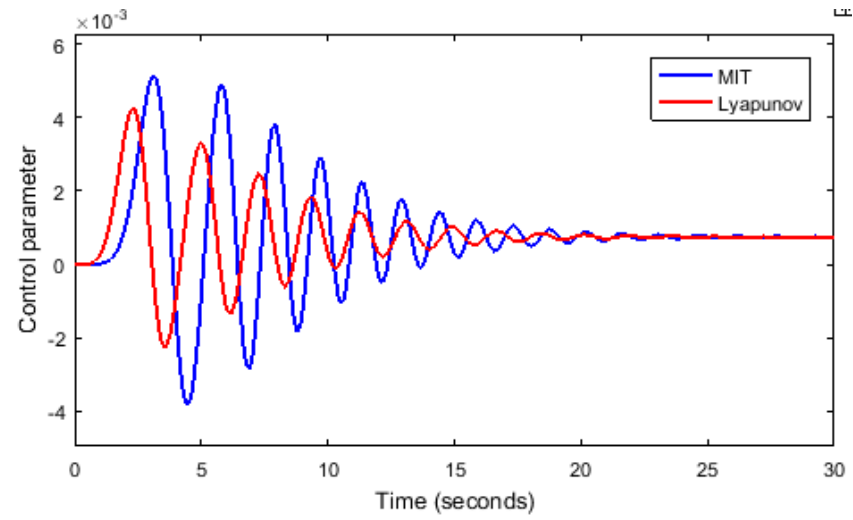

(a) noninteracting shown in Fig 14(b) converge to constant values of $7.4826-4$ (MIT rule) and 7.4806E - 4 (Lyapunov rule) and converge to constant values of 7.5011E - 4 (MIT rule) and 7.5141E - 4 (Lyapunov rule).

The control parameters are used to improve the plant parameters, $a$ and $b$, so that the plant adequately tracks the reference model. Using the fixed adaptation gain MRAC and FOMRAC systems based on the MIT and Lyapunov rules, Figs. 15 - 18 show the response characteristics for the plants and reference models of the noninteracting and interacting tank systems. It is observed that the plant adequately tracks the reference model in all systems.

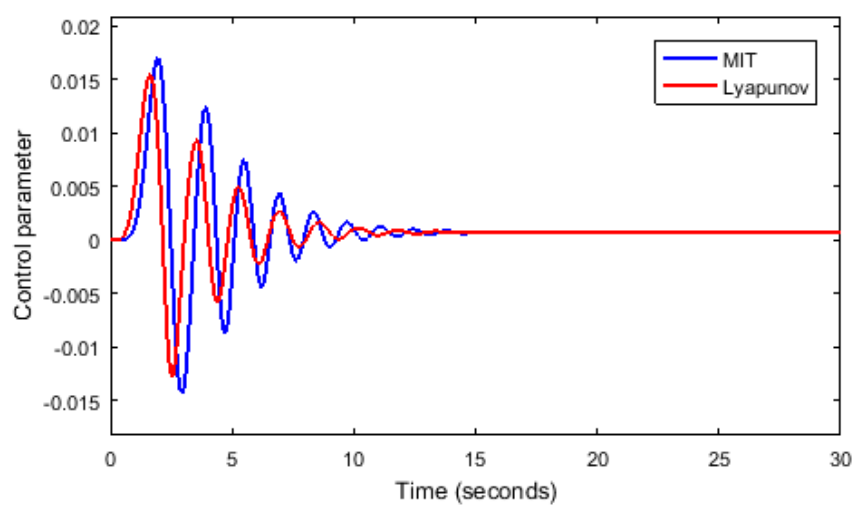

(b) interacting

Figure 13. Variations in control parameters of the fixed adaptation gain MRAC systems

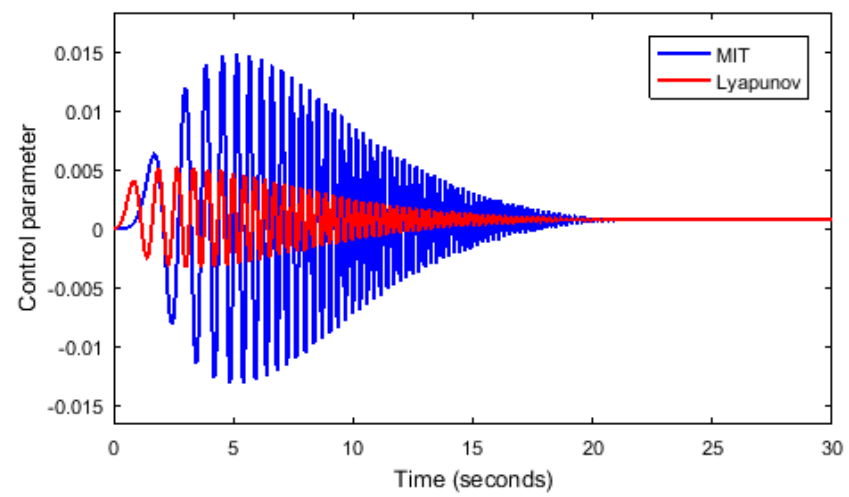

(a) noninteracting

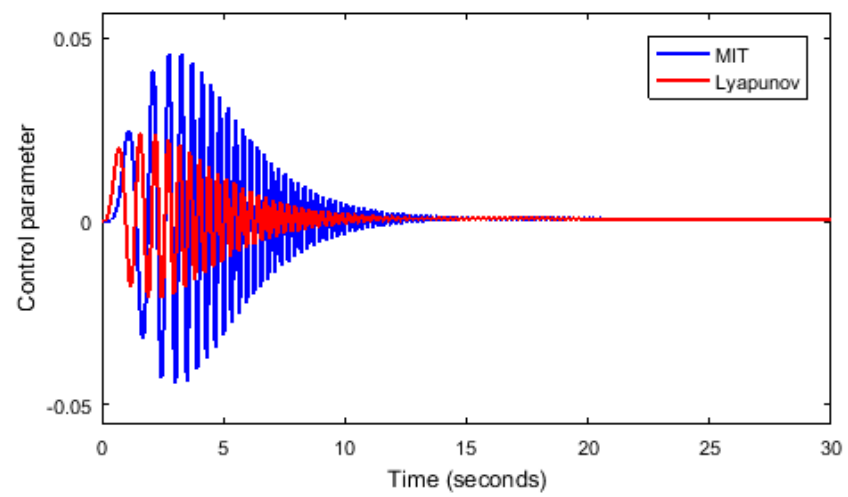

(b) interacting

Figure 14. Variations in control parameters of the FOMRAC systems

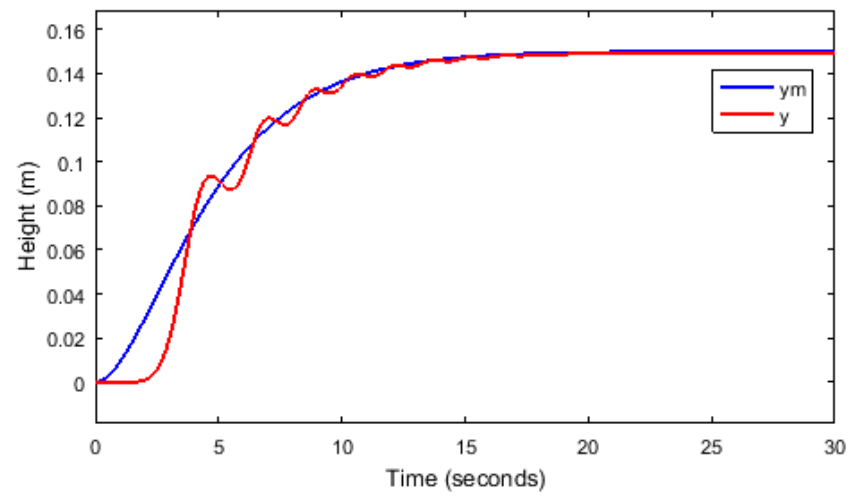

(a) noninteracting

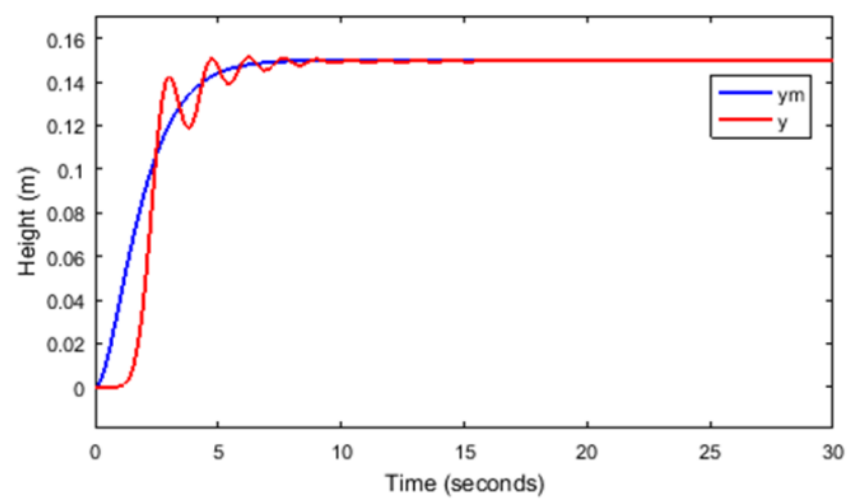

(b) interacting

Figure 15. Response characteristics for the reference model and plant of the fixed adaptation gain MRAC systems based on MIT rule 


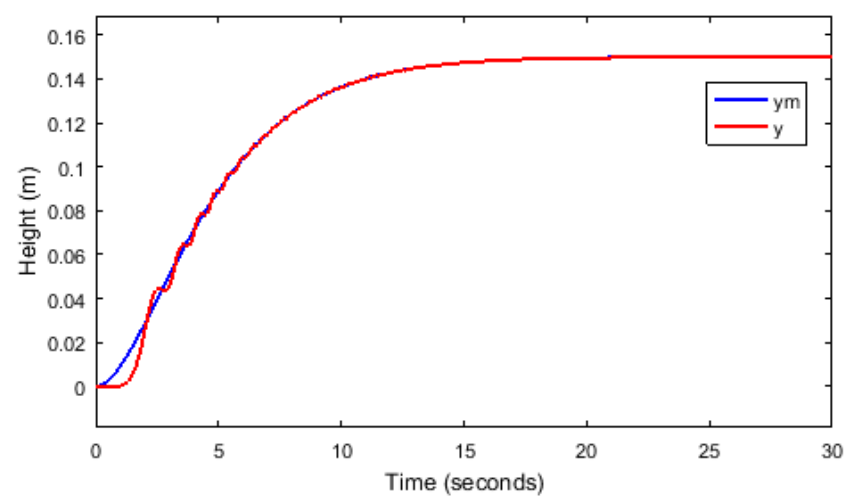

(a) noninteracting

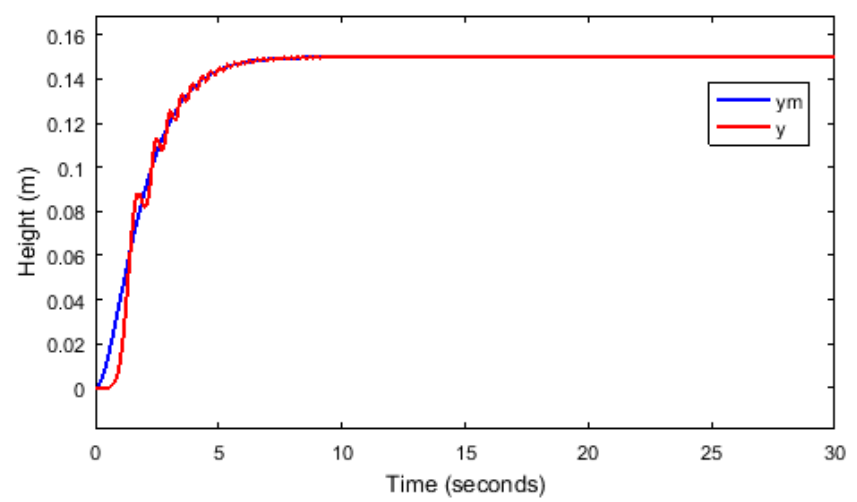

(b) interacting

Figure 16. Response characteristics for the reference model and plant of the FOMRAC systems based on MIT rule

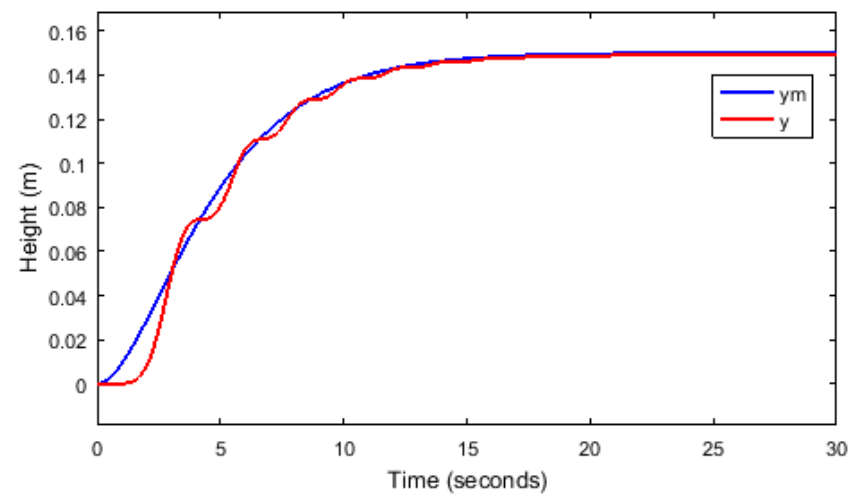

(a) noninteracting

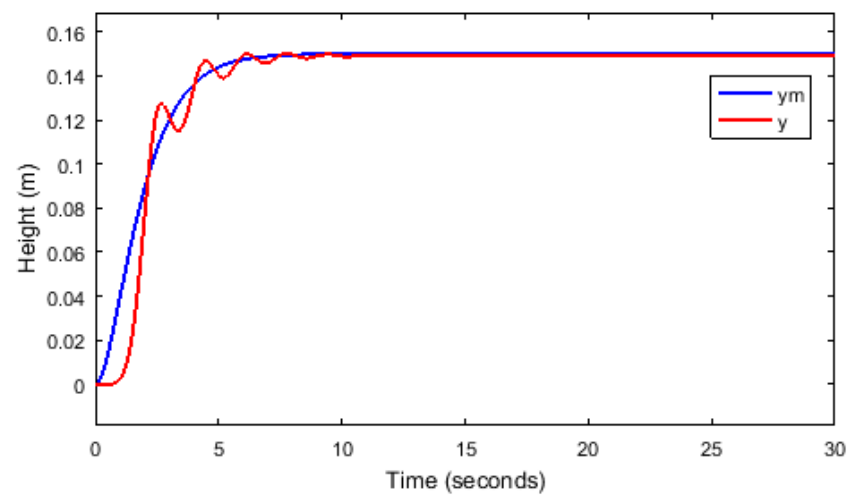

(b) interacting

Figure 17. Response characteristics for the reference model and plant of the fixed adaptation gain MRAC systems based on Lyapunov rule

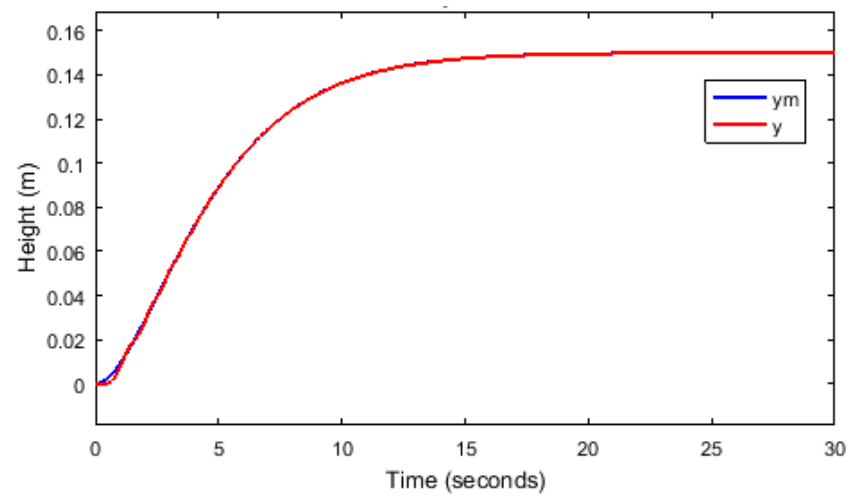

(a) noninteracting

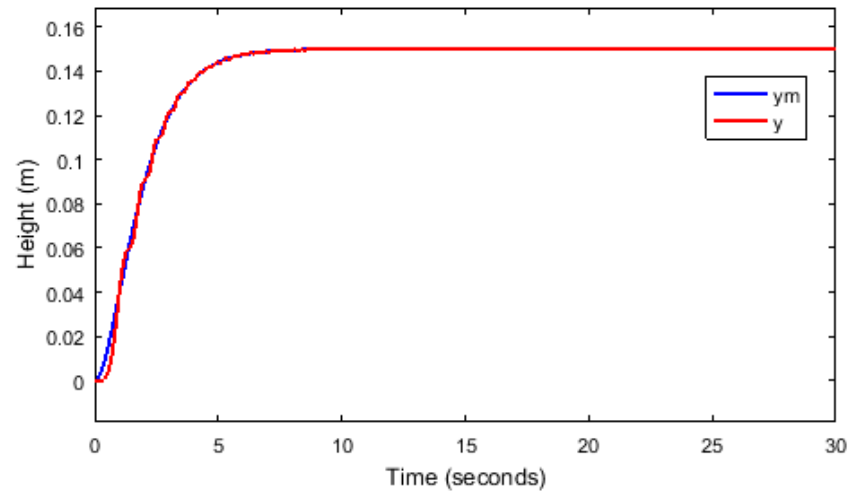

(b) interacting

Figure 18. Response characteristics for the reference model and plant of the FOMRAC systems based on Lyapunov rule

As the plants track the reference models, the error is reduced to zero. The error plots of the systems for the fixed adaptation gain MRAC and FOMRAC systems based on the MIT and Lyapunov rules are shown in Fig. 19. The performance indices: ISE, IAE, ITAE and ITSE are used for comparative analysis based on the error plots of the controllers. This is shown in Table 7. It is seen that the FOMRAC system based on the Lyapunov rule obtained the least fitness values.

The output/response curves for a set point $\left(h_{2}\right)$ of $0.15 \mathrm{~m}$ of all four control schemes for the noninteracting and interacting tank systems are shown in Fig. 20. It is observed from the plot characteristics shown in Table 8 that the fixed adaptation gain MRAC systems and FOMRAC scheme exhibit zero overshoot for the noninteracting tank system. On the other hand, the FOMRAC scheme based on Lyapunov rule completely eliminates the slight overshoot that resulted from the implementation of the other three control schemes for the interacting tank system. In comparison to the fixed adaptation gain MRAC systems, the FOMRAC systems have better steady state errors. Furthermore, the FOMRAC scheme based on Lyapunov rule has the fastest settling time for both the noninteracting and interacting tank systems.

Finally, it is common knowledge that adaptive controllers prevail under changing model parameters. Hence, to establish that the controllers can adequately deal with parameter variations or disturbances, all controllers are simulated for a unit ramp reference input and the result is shown in Fig. 21. It is seen that all four controllers adequately track the reference input. 


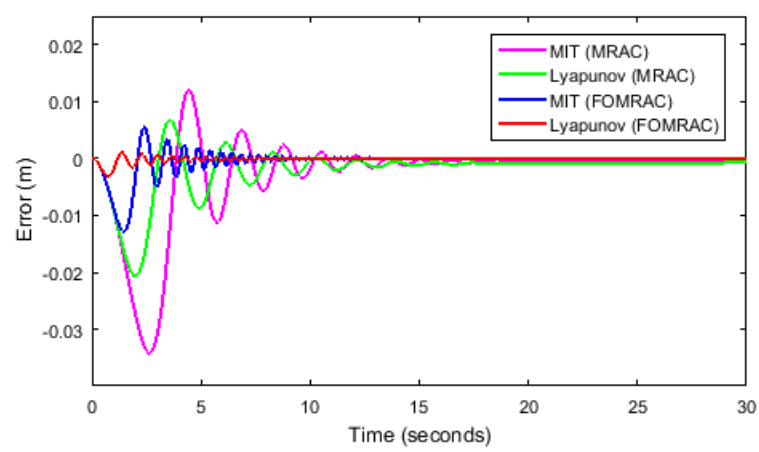

(a) noninteracting

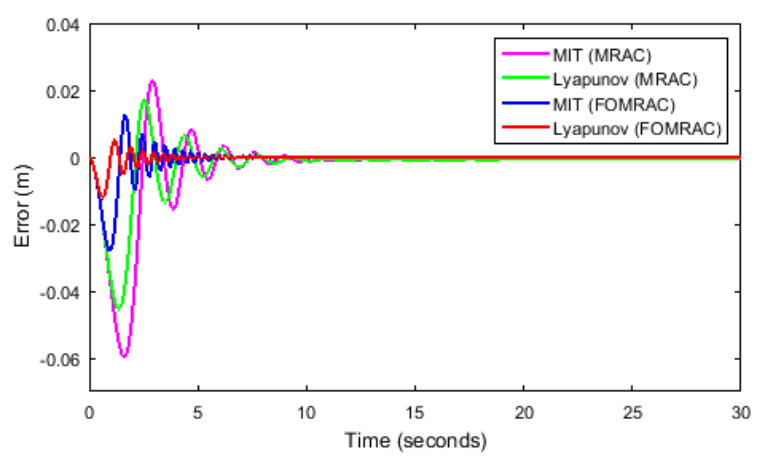

(b) interacting

Figure 19. Error plots for the fixed adaptation gain MRAC systems and the FOMRAC systems

Table 7. Performance indices of each control type for both coupled tank systems

\begin{tabular}{|c|c|c|c|c|c|}
\hline \multirow{2}{*}{ System } & \multirow{2}{*}{ Control Type } & \multicolumn{4}{|c|}{ Objective Functions } \\
\hline & & ISE & IAE & ITAE & ITSE \\
\hline \multirow{4}{*}{ Noninteracting } & MIT (MRAC) & $1.968 \mathrm{E}-3$ & $1.100 \mathrm{E}-1$ & $5.743 \mathrm{E}-1$ & $5.633 \mathrm{E}-3$ \\
\hline & Lyapunov (MRAC) & $6.347 \mathrm{E}-4$ & $7.164 \mathrm{E}-2$ & $5.126 \mathrm{E}-1$ & $1.813 \mathrm{E}-3$ \\
\hline & MIT (FOMRAC) & $1.566 \mathrm{E}-4$ & $2.396 \mathrm{E}-2$ & $6.762 \mathrm{E}-2$ & $2.628 \mathrm{E}-4$ \\
\hline & Lyapunov (FOMRAC) & $6.490 \mathrm{E}-6$ & $4.898 \mathrm{E}-3$ & $1.610 \mathrm{E}-2$ & $8.021 \mathrm{E}-6$ \\
\hline \multirow{4}{*}{ Interacting } & MIT (MRAC) & $4.030 \mathrm{E}-3$ & $1.262 \mathrm{E}-1$ & $4.741 \mathrm{E}-1$ & $7.022 \mathrm{E}-3$ \\
\hline & Lyapunov (MRAC) & $2.101 \mathrm{E}-3$ & $9.656 \mathrm{E}-2$ & $4.572 \mathrm{E}-1$ & $3.413 \mathrm{E}-3$ \\
\hline & MIT (FOMRAC) & $5.199 \mathrm{E}-4$ & $3.533 E-2$ & $6.485 \mathrm{E}-2$ & $5.671 \mathrm{E}-4$ \\
\hline & Lyapunov (FOMRAC) & $7.529 E-5$ & $1.322 \mathrm{E}-2$ & $2.575 \mathrm{E}-2$ & $6.442 \mathrm{E}-5$ \\
\hline
\end{tabular}

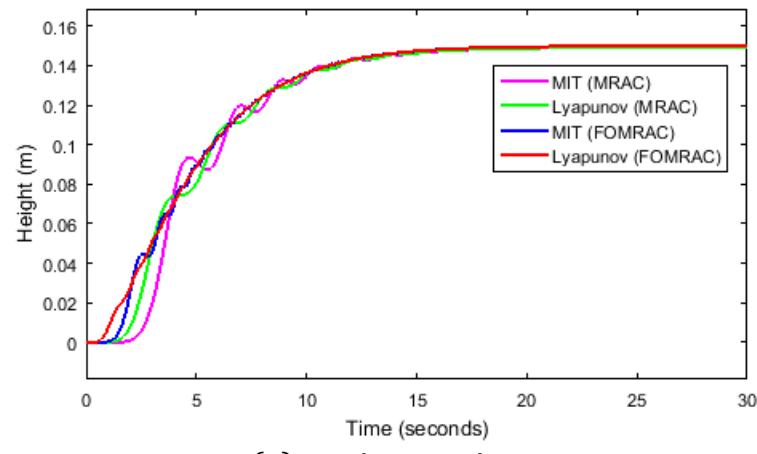

(a) noninteracting

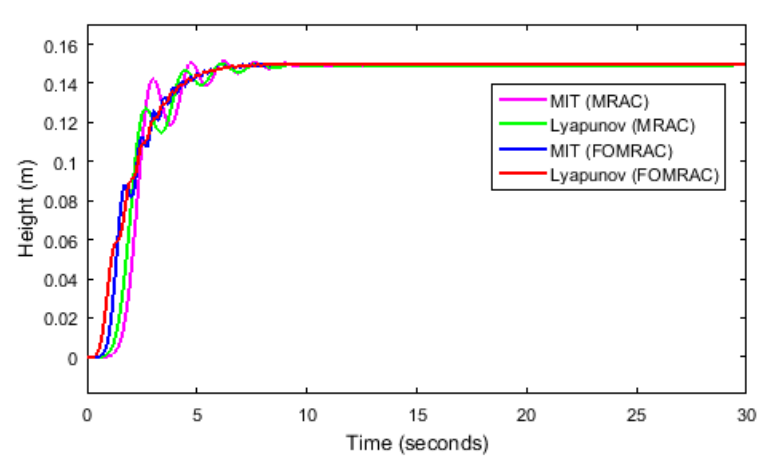

(b) interacting

Figure 20. Response plots for a set point of $0.15 \mathrm{~m}$

Table 8. Plot characteristics of the response plots for a set point of $0.15 \mathrm{~m}$

\begin{tabular}{llcccc}
\hline \multirow{3}{*}{ System } & & \multicolumn{4}{c}{ Objective Functions } \\
\cline { 3 - 5 } & Control Type & $\begin{array}{c}\text { Rise Time } \\
(\mathrm{s})\end{array}$ & $\begin{array}{c}\text { Percentage } \\
\text { Overshoot (\%) }\end{array}$ & $\begin{array}{c}\text { Steady State Error } \\
(\mathrm{m})\end{array}$ & $\begin{array}{c}\text { Settling } \\
\text { Time }(\mathrm{s})\end{array}$ \\
\hline \multirow{3}{*}{ Noninteracting } & MIT (MRAC) & 7.1491 & 0 & $-5.1644 \mathrm{E}-4$ & 14.7653 \\
& Lyapunov (MRAC) & 7.5781 & 0 & $-7.2903 \mathrm{E}-4$ & 15.0728 \\
& MIT (FOMRAC) & 7.8797 & 0 & $-1.9823 \mathrm{E}-5$ & 14.6085 \\
& Lyapunov (FOMRAC) & 8.4349 & 0 & $-2.0624 \mathrm{E}-5$ & 14.5798 \\
\hline \multirow{3}{*}{ Interacting } & MIT (MRAC) & 1.1062 & 1.2648 & $-4.8290 \mathrm{E}-4$ & 7.1279 \\
& Lyapunov (MRAC) & 2.6083 & 0.4622 & $-6.0940 \mathrm{E}-4$ & 7.0991 \\
& MIT (FOMRAC) & 2.7983 & 0.0121 & $-7.5632 \mathrm{E}-6$ & 6.1365 \\
& Lyapunov (FOMRAC) & 3.0678 & 0 & $-8.1561 \mathrm{E}-6$ & 5.8708 \\
\hline
\end{tabular}

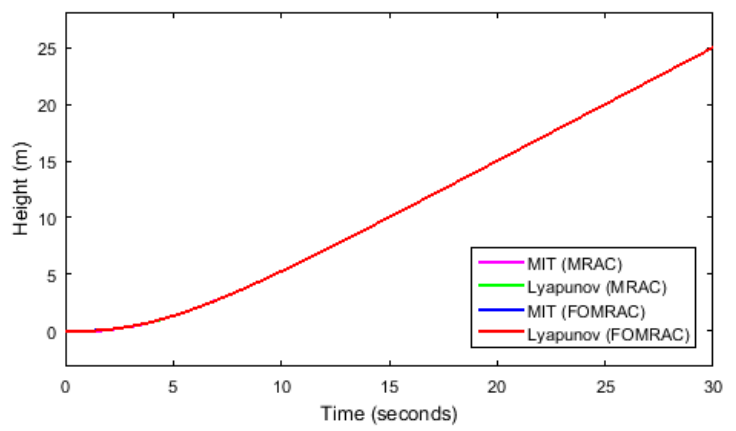

(a) noninteracting

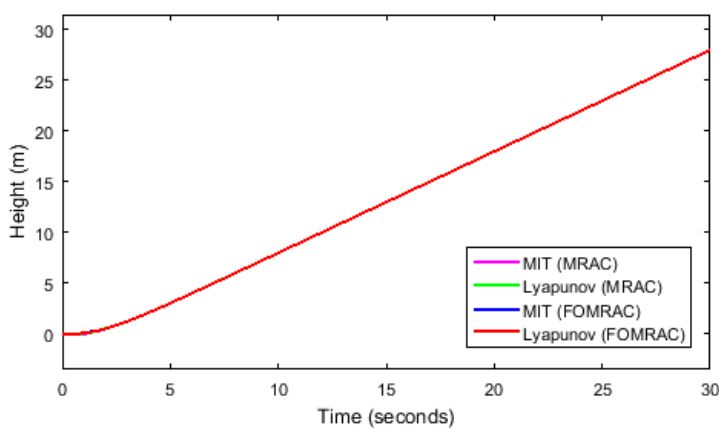

(b) interacting

Figure 21. Response plots for a unit ramp input 


\section{CONCLUSION}

MRAC has proven to be adequately capable of handling systems with constant parameter changes as visibly portrayed in the results. The performance of the fuzzy-optimized MRAC systems based on the MIT and Lyapunov rules were compared with the performance of conventional fixed adaptation gain MRAC systems, for the control of the level and flow of liquid in coupled twotank systems arranged in noninteracting and interacting setups. In both tank setups, it was observed that there were longer settling times when the fixed adaptation gain MRAC systems were adopted as opposed to the FOMRAC systems. Specifically, the FOMRAC system based on Lyapunov rule eliminated the resulting overshoot from the implementation of the other three schemes for the control of interacting processes. Also, the FOMRAC scheme based on Lyapunov rule had the least objective function values, thus, making it the ideal control strategy for noninteracting and interacting processes.

\section{ACKNOWLEDGEMENT}

The authors sincerely appreciate the National Information Technology Development Agency (NITDA) for the research grant provided to carry out this work through the National Information Technology Development Fund (NITDEF). Ref: NITDA/HQ/DG/135/2005/VOL.2.

\section{REFERENCES}

Amat M A H C, Naim S \& Zakaria S (2018). Fuzzy logic approach to identify deprivation index in Peninsular Malaysia. Bulletin of Electrical Engineering and Informatics, $7(4)$

601-608. DOI: $10.11591 /$ eei.v7i4.1352

Astrom K J \& Wittenmark B (1989). Adaptive Control, Addison-Wesley, USA.

Atchaya, G. (2017). "Review of linear and non-linear liquid level control system." Journal of Innovative Science \& Engineering Research, 2(2), 3-7.

Ayten K K, Dumlu A \& Kaleli A (2018). Real-time implementation of self-tuning regulator control technique for coupled tank industrial process system. Proceedings of the Institution of Mechanical Engineers, Part I: Journal of Systems and Control Engineering, 1-14. DOI: $10.1177 / 0959651818773179$

Bhuvaneswari N S, Praveena R \& Divya R (2012). System identification and modeling for interacting and noninteracting tank systems using intelligent techniques. arXiv preprint, arXiv: 1208.1103.

Changela M \& Kumar A (2015). Designing a controller for two tank interacting system. International Journal of Science and Research (IJSR), 4(5), 589-593.

Cheung J Y M (1996). A fuzzy logic model reference adaptive controller. IEE Colloquium on Adaptive Controllers in practice, 1-6.

Cheung J Y M, Cheng K W E \& Kamal A S (1996). Motor speed control by using a fuzzy logic model reference adaptive controller. 6th International Conference on
Power Electronics and Variable Speed Drives, 430435.

Coughanowr D R \& LeBlanc S E (2009). Process systems analysis and control, McGraw-Hill, New York, USA. ISBN: 978-0-07-339789-4

Damrudhar O and Tanti D K (2016). Comparative performance analysis for two tanks liquid level control system with various controllers using MATLAB. International Journal of Latest Trends in Engineering and Technology (IJLTET), 7(2), 345-352. DOI:10.21172/1.72.555

Dinakin D D \& Oluseyi P O (2018). Optimal underfrequency load curtailment via continuous load control in a single area power system using fuzzy logic, PID-fuzzy and neuro-fuzzy (ANFIS) controllers. Jordan Journal of Electrical Engineering (JJEE), 4(4), 208-223.

Dumont G (2011). EECE 574 - Adaptive Control, Lecture notes - Model Reference Adaptive Control.

Fellani M A \& Gabaj A M (2015). PID controller design for two tanks liquid level control system using MATLAB. International Journal of Electrical and Computer Engineering (IJECE), 5(3), 436-442.

Jain P \& Nigam M J (2013). Design of a model reference adaptive controller using modified MIT rule for a second order system. Advance in Electronic and Electric Engineering, 3(4), 477-484.

Jang L K (2017). Feedback control for liquid level in a gravity-drained multi-tank system. Chemical Engineering \& Process Techniques, 3(1), 1-10.

John J A, Jaffar N E \& Francis R M (2015). Modeling and control of coupled tank liquid level system using backstepping method. International Journal of Engineering Research \& Technology (IJERT), 4(6), 667-671.

Keerth K \& Sathyanarayana M S (2012). Fuzzy implementation of model reference adaptive control of DC drives. International Journal of Engineering Science and Advanced Technology (IJESAT), 2(3), 605-611.

Lavanya M, Aravind P, Valluvan M \& Caroline B E (2013). Model based control for interacting and noninteracting level process using labview. International Journal Advanced Research in Electrical, Electronics and Instrumentation Engineering, 2(7), 3174-3179.

Mamur H, Atacak I, Korkmaz F \& Bhuiyan M R A (2017). Modeling and application of a computer-controlled liquid level tank system. Computer science \& Information Technology (CS \& IT), pp. 97-106.

Manohar G, Elakkiya V, Stanley P \& Sudha R (2013). Neural network based level control in two tank conical interacting system. 7th International Conference on Intelligent Systems and Control (ISCO), 194-196.

MATLAB (2016). Natick, Massachusetts: The MathWorks, Inc., version 9.0.0.341360.

Medewar P G, Sonawane R R \& Munje R K (2017). Two tank non-interacting liquid level control comparison using fuzzy and PSO controller. National Conference on Emerging Trends in Engineering \& Technology (NCETET17), IOSR Journal of Electrical and Electronics Engineering (IOSR-JEEE), 1(5), 24-31. 
Mekhanet M, Mokrani L, Ameur A \& Attia Y (2016). Adaptive fuzzy gain of power system stabilizer to improve the global stability. Bulletin of Electrical Engineering and Informatics, 5(4), 421-429. DOI: 10.11591/eei.v5i4.576

Nandhinipriyanka G, Ishwarya S, Janakiraman S, Thana C S \& Vaishali P (2018). Design of model reference adaptive controller for cylinder tank system. International Journal of Pure and Applied Mathematics, 118(20), 2007-2013.

Narayan Y \& Srivastava S (2013). Response of flow rate of non-interacting tanks using NCS and fuzzy controller. 2013 International Conference on Emerging Trends in Communication, Control, Signal Processing \& Computing (C2SPCA), 1-4.

Nasar A, Jaffar N E \& Kochummen S A (2015). Lyapunov rule based model reference adaptive controller designs for steam turbine speed. International Journal of Electrical Engineering \& Technology (IJEET), 6(7), 13-22.

Pankaj S, Kumar J S \& Nema R K (2011). Comparative analysis of MIT rule and Lyapunov rule in model reference adaptive control scheme. Innovative Systems Design and Engineering, 2(4), 154-162.

Parvat B J, Deo S A \& Kadu C B (2015). Mathematical modeling of interacting and non interacting system. International Journal of Application or Innovation in Engineering \& Management (IJAIEM), 4(1), 86-92.

Reusch B (1997). Computational Intelligence Theory and Applications. Proceedings of International Conference, 5th Fuzzy Days, Dortmund, Germany, Springer. ISBN: 978-3-540-69031-3

Saju S, Revathi R \& Suganya K P (2014). Modeling and control of liquid level non-linear interacting and noninteracting system. International Journal of Advanced Research in Electrical, Electronics and Instrumentation Engineering, 3(3), 8003-8013.
Salunkhe S M, Kurode S R \& Bhole V B (2015). Robust control of liquid level in coupled tank system using smooth first order sliding modes. 2015 International Conference on Industrial Instrumentation and Control (ICIC), pp. 1647-1650.

Senapati A, Maitra N, Batabyal S \& Kashyap A K (2018). Control and performance analysis of three tank flow control system using linear \& non-linear controller. International Journal of Innovative Research in Computer and Comunication Engineering, 6(1), 329340. DOI: 10.15680/IJIRCCE.2018. 0601057

Senthilkumar M \& Lincon S A (2012). Design of stabilizing PI controller for coupled tank MIMO process. International Journal of Engineering Research and Development, 3(10), 47-55.

Stellet J E (2011). Influence of adaptation gain and reference model parameters on system performance for model reference adaptive control. International Scholarly and Scientific Research \& Innovation, 5(12), 1660-1665.

Swarnkar P, Jain S \& Nema R K (2011). Effect of adaptation gain in model reference adaptive controlled second order system. Engineering, Technoloy \& Applied Science Research, 1(3), 70-75.

Tijani A S, Shehu M A, Alsabari A M, Sambo Y A \& Tanko N L (2017). Performance analysis for coupled-tank system liquid level control using MPC, PI, PI-plusfeedforward control scheme. Journal of Robotics and Automation, 1(1), 42-53.

Zhang P (2010). Advanced Industrial Control Technology, William Andrew, New York, USA. ISBN13:978-1-4377-7807-6

Zadeh L A (1975). The concept of a linguistic variable and its application to approximate reasoning - I. Information Sciences, 8, 199-249. DOI: 10.1016/0020-0255(75)90036-5 